\title{
Immediate and Late Mandibular Fractures After Third Molar Removal
}

\author{
Philippe Libersa, DMD, PhD, * David Roze, DMD, $†$ \\ Thierry Cachart, DMD, $\ddagger$ and Jean-Claude Libersa, DMD, PhD』
}

\begin{abstract}
Purpose: In this retrospective study, we analyzed immediate and late mandibular fractures after impacted lower third molar surgery.

Patients and Methods: One hundred fifty oral and maxillofacial surgeons in the north of- France were questioned about their experience with intraoperative and late mandibular fracture after third molar surgery. Cases were examined clinically and radiographically.
\end{abstract}

Results: Thirty-seven fractures were reported in about 750,000 extractions (incidence of $0.0049 \%$ ). Only 27 cases could be precisely described: 17 intraoperative and 10 late fractures. The patients were 19 to 75 years of age, with an average age of 37 years for intraoperative fractures and 47 years for late fractures. All grades of tooth impaction were included. Only 2 patients did not have full dentition.

Conclusions: The major incidence of immediate and late mandible fractures occurs in patients older than over 25 years. Men may be more likely to have late fractures ( 8 of 10 cases).

(C) 2002 American Association of Oral and Maxillofacial Surgeons

J Oral Maxillofac Surg 60:163-165, 2002

The mandible is the most commonly fractured facial bone a fact directly related to its prominent and exposed location. ${ }^{1}$ Fractures through the angle are frequent ${ }^{2}$ because the angle of the mandible forms an area of lowered resistance with a thicker superior border, thin basilar bone, ${ }^{3,4}$ and the presence of the impacted mandibular third molar. Reports of mandibular fracture after third molar removal are uncommon..$^{5-7}$ This retrospective survey of the 10-year experience of 150 oral and maxillofacial surgeons in northern France was designed to determine the occurrence of intraoperative and postoperative mandibular fracture, the incidence, and the predisposing factors.

\section{Patients and Methods}

One hundred fifty oral and maxillofacial surgeons were questioned about their experience with intraop-

\footnotetext{
*Assistant Professor, Odontology Unit, Centre Abel Caumartin, CHRU Lille, France.

†Resident, Odontology Unit, Centre Abel Caumartin, CHRU Lille, France.

$\ddagger$ Private Practice, Carvin, France.

\Head, Clinical Professor, Odontology Unit, Centre Abel Caumartin, CHRU Lille, France.

Address correspondence and reprint requests to Dr Libersa: 60, la Posterie 59830 Bourghelles, France; e-mail: sylvie.libersa3@ libertysurf.fr

(1) 2002 American Association of Oral and Maxillofacial Surgeons

0278-2391/02/6002-0005\$35.00/0

doi: $10.1053 /$ joms.2002.29811
}

erative and postoperative mandibular fracture after third molar removal. The survey covered the 10-year period between 1989 and 1999. The patients with immediate or late fracture were selected, and their age, gender, dentition, type of impaction, medical history, radiologic evaluation, and type of surgery were assessed. Furthermore, the surgeons specified how the fracture occurred.

\section{Results}

Thirty-seven unilateral fractures among an estimated 750,000 impacted mandibular third molar removals were reported by 150 surgeons for the 10-year period. All of the surgeons have been in practice for at least 10 years. Only 27 of the 37 fractures are included in this study due to a lack of specific information for 10 of them. Seventeen of the fractures occurred intraoperatively (Fig 1), and 10 occurred postoperatively. Thirteen occurred with the patient under general anesthesia, and 14 occurred with the patient under local anesthesia. Only 1 was displaced (Fig 2). Twenty-two teeth were full bony and 5 were partial bony impactions (Table 1).

Patients' ages ranged from 19 to 75 years (average of 40 years), with an average of 37 years for immediate fractures and 47 years for late fractures. Two patients were younger than 20 years and 23 of 27 were older than 25 years (Table 2). Twelve patients were female: 10 with intraoperative fractures and 2 with late ones. Fifteen patients were male, 7 with intraoperative fractures and 8 with late ones. The 


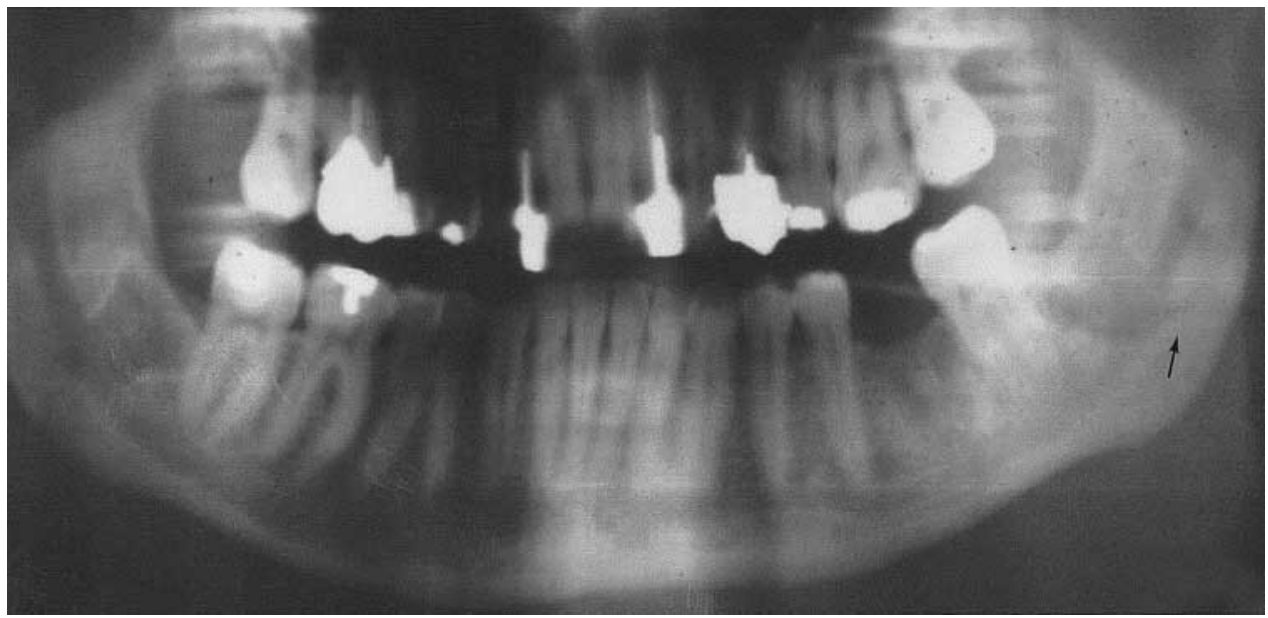

FIGURE 1. Panoramic radiograph of a 33-year-old patient showing an intraoperative nondisplaced mandibular fracture after lower vertical third molar removal on the left side (arrow).

patients' medical histories revealed 1 case of osteoporosis and 1 case of a large cyst associated with the impacted third molar (Fig 2). The late fractures occurred between postoperative days 13 and 21, at a mean of 16 days (Table 3). Fractures occurred during mastication in 6 of 9 cases. All of the patients noticed a cracking sound and a renewed pain in the area of the extraction. Two additional fractures occurred after postextraction osteitis, and 1 occurred after "a cry of fear."

\section{Discussion}

The angle of the mandible is an area of lowered resistance to fracture, due to its specific osseous anatomy and its location between the ramus and the corpus. ${ }^{8}$ Thus, it is an area that frequently sustains fracture. Mandibular fractures after impacted third molar removal are rare. The present study, in which we obtained an incidence of $0.0049 \%$, confirms the conclusion of Perry and Goldberg. ${ }^{7}$ Intraoperative fractures may occur with improper instrumentation and excessive force to the bone. This confirms the importance of tooth sectioning before extraction, but it cannot account for all of the complications. Should the mode of anesthesia for surgery not influence mandibular fractures, the type of impaction seems to be significant. Similar to the findings of Krimmel and Reinert ${ }^{5}$ and Perry and Goldberg, ${ }^{7}$ We found a greater incidence of mandibular fracture with full bony impactions, presumably because a greater volume of bone is necessary for removal. Similar to other investigators' $5-7,9$ we found that patient age is an important factor in fracture risk. Eighty-five percent of the patients were older than 25 years, with a mean age of 40 years, whereas the usual age range for third molar removal in France is about 15 to 20 years. Only 1 patient had osteoporosis, so this does not explain the age group distribution. Gender seems to be particularly important in postoperative fractures. Only 2 women sustained postoperative fractures, whereas 8 men did. Perhaps this is due to the greater masticatory force in men. Most late fractures occurred between 13 and 21 days after surgery, the main cause being
FIGURE 2. Panoramic radiograph of a 42-year-old patient showing a postoperative 115 days) displaced mandibular fracture after lower third molar removal on the left side (arrow). Note the bone defect due to a pericoronal cyst.

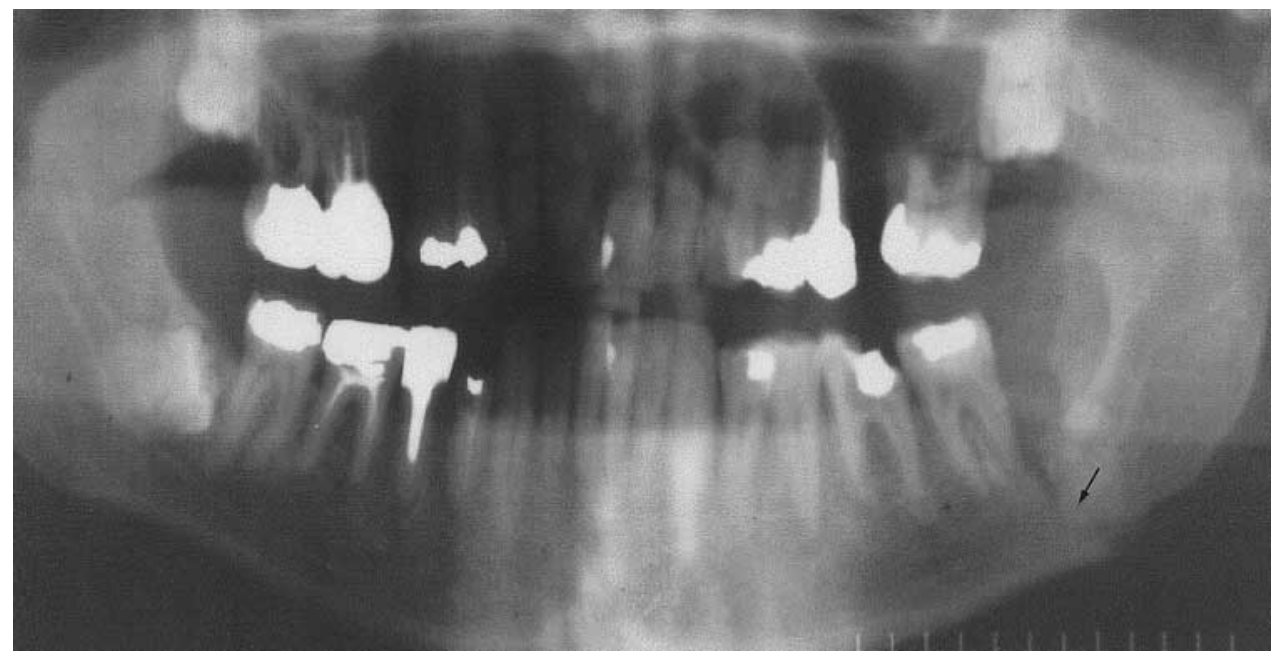


Table 1. TYPE OF IMPACTED TOOTH

\begin{tabular}{lcc} 
Anatomic Position & Partial Bony (n) & Full Bony (n) \\
\hline Horizontal & 4 & 9 \\
Vertical & 0 & 9 \\
Mesioangular & 0 & 2 \\
Distoangular & 1 & 2 \\
Total & 5 & 22 \\
\hline
\end{tabular}

mastication. The greatest risk period seems to be during postoperative weeks 2 and $3,^{7}$ during which granulation tissue is being replaced by connective tissue in the alveolar socket. ${ }^{10}$ Moreover, at the end of the second week, patients are feeling better, the pain has disappeared, and they can masticate normally. When the patients have a full dentition, the occlusal forces are at their peak and the risk of fracture in non-fully calcified mandibles is very great. Our survey confirms the results of the study of Perry and Goldberg, ${ }^{7}$ especially because most of the patients reported a cracking sound during eating that was accompanied by great pain. The risk seems greater among men, particularly for those who are older than

\section{Table 2. AGE OF PATIENTS SUSTAINING A LATE OR} IMMEDIATE FRACTURE

\begin{tabular}{ccc} 
& \multicolumn{2}{c}{ No. of Patients } \\
\cline { 2 - 3 } Age of Patient $(\mathrm{yr})$ & Immediate Fracture & Late Fracture \\
\hline $16-19$ & 2 & 0 \\
$20-25$ & 2 & 0 \\
$26-35$ & 5 & 3 \\
$36-45$ & 5 & 3 \\
$>45$ & 3 & 4 \\
Total & 17 & 10 \\
\hline
\end{tabular}

Table 3. INTERVAL FROM REMOVAL TO FRACTURE

\begin{tabular}{cc} 
Postoperative Day & No. of Patients \\
\hline $10-14$ & 3 \\
$15-20$ & 6 \\
$>20$ & 1 \\
\hline
\end{tabular}

25 years. These patients should be informed of the possibility of mandibular fracture and the desirability of masticatory limiting force for 2 months. Prophylactic third molar removal before 20 years of age should mitigate nearly all risk of fracture.

\section{References}

1. Banks P: Killey's Fractures of the Mandible (ed 4). London, England, Wright, 1991, p 1

2. Ellis E, Sinn DP: Treatment of the mandibular angle fractures using $2.4 \mathrm{~mm}$ dynamic compression plates. J Oral Maxillofac Surg 51:969, 1993

3. Assael L: Treatment of mandibular angle fractures. J Oral Maxillofac Surg 52:757, 1994

4. Kruger E: Mandibular fractures, in Kruger E, Schilli W (eds): Oral Maxillofacial Traumatology. Chicago, IL, Quintessence, 1982, pp 211-236

5. Krimmel M, Reinert S: Mandibular fracture after third molar removal. J Oral Maxillofacial Surg 58:1110, 2000

6. Lizuka T, Tanner S, Berthold H: Mandibular fractures following third molar extraction: A retrospective clinical and radiological study. Int J Oral Maxillofac Surg 26:338, 1997

7. Perry PA, Goldberg MH: Late mandibular fracture after third molar surgery: A survey of Connecticut oral and maxillofacial surgeons. J Oral Maxillofac Surg 58:858, 2000

8. Ferre JC: Etude mécanique de la mandibule à l'aide des méthodes modernes utilisées en résistance des matériaux. Rev Stomatol Chir Maxillo Fac 82:258, 1981

9. Bruce RA, Frederickson GC, Small G: Age of patients and morbidity associated with mandibular third molar surgery. J Am Dent Assoc 101:240, 1980

10. Amler MH, Johnson PL, Salman I: Histological and histochemical investigation of human alveolar socket healing in undisturbed extraction wounds. J Am Dent Assoc 61:33, 1960 